\title{
Burkholderia ferrariae sp. nov., isolated from an iron ore in Brazil
}

\author{
Angel Valverde, ${ }^{1} \dagger$ Pedro Delvasto, ${ }^{2}$ Alvaro Peix, ${ }^{1}$ Encarna Velázquez, ${ }^{3}$ \\ Ignacio Santa-Regina, ${ }_{1}^{1}$ Antonio Ballester, ${ }^{2}$ Claudino Rodríguez-Barrueco, ${ }^{1}$ \\ Camino García-Balboa ${ }^{4}$ and José M. Igual ${ }^{1}$ \\ ${ }^{1}$ Instituto de Recursos Naturales y Agrobiología de Salamanca, Consejo Superior de \\ Investigaciones Científicas, 37071 Salamanca, Spain \\ ${ }^{2}$ Biohydrometallurgy Research Group, Department of Materials Science and Metallurgical \\ Engineering, Universidad Complutense de Madrid, 28040 Madrid, Spain \\ ${ }^{3}$ Departamento de Microbiología y Genética, Universidad de Salamanca, 37007 Salamanca, \\ Spain \\ ${ }^{4}$ Department of Industrial Technology, Universidad Alfonso X 'El Sabio', Av. de la Universidad 1, \\ 28691 Villanueva de la Cañada, Madrid, Spain
}

Correspondence

José M. Igual

igual@usal.es

\begin{abstract}
A Gram-negative, non-spore-forming bacterial strain with the ability to solubilize highly insoluble phosphatic minerals was isolated from a high-phosphorous iron ore from Minas Gerais State, Brazil. This strain, designated FeGl01 ${ }^{\top}$, was subjected to a polyphasic taxonomic investigation. Comparative 16S rRNA gene sequence analysis indicated that it formed a distinct phylogenetic lineage within the genus Burkholderia together with several other species of the genus, e.g. Burkholderia sacchari, Burkholderia tropica and Burkholderia unamae. Partial nucleotide sequencing and analysis of the $\operatorname{rec} A$ gene roughly corroborated the phylogenetic position of strain $\mathrm{FeGl01}{ }^{\top}$ within the genus Burkholderia. The chemotaxonomic properties of strain $\mathrm{FeGl01}{ }^{\top}$, such as ubiquinone $\mathrm{Q}-8$ as the predominant quinone system and $\mathrm{C}_{16: 0}, \mathrm{C}_{17: 0}$ cyclo, $\mathrm{C}_{18: 1} \omega 7 \mathrm{c}$ and $\mathrm{C}_{19: 0} \omega 8 \mathrm{c}$ cyclo as the major fatty acids, were also consistent with its classification within the genus Burkholderia. DNA-DNA hybridization experiments between strain $\mathrm{FeGlO}^{\top}$ and the type strains of $B$. unamae, $B$. sacchari and $B$. tropica yielded reassociation values of $40 \%$ or lower, which, together with qualitative and quantitative differences in fatty acid composition and with differences in several phenotypic traits, support the separation of the new isolate from the phylogenetically most closely related species. Therefore, it is suggested that strain $\mathrm{FeGl01}{ }^{\top}$ represents a novel species of the genus Burkholderia, for which the name Burkholderia ferrariae sp. nov. is proposed. The type strain is FeGl01 ${ }^{\top}\left(=\right.$ LMG $23612^{\top}=$ CECT $7171^{\top}=$ DSM $\left.18251^{\top}\right)$.
\end{abstract}

Since Yabuuchi et al. (1992) proposed the genus Burkholderia to include the former rRNA group II pseudomonads, many other bacterial species have been described as belonging to this genus, which at the time of

†Present address: Department of Plant Pathology and Microbiology, Faculty of Agricultural, Food and Environmental Quality Sciences, The Hebrew University of Jerusalem, Rehovot 76100, Israel.

Abbreviation: PSM, phosphate-solubilizing micro-organism.

The GenBank/EMBL/DDBJ accession number for the 16S rRNA gene sequence of $B$. ferrariae $\mathrm{FeGIO1^{ \top }}$ is D0514537 and the accession numbers for the recA gene sequences of $B$. ferrariae $\mathrm{FeGl0} 1^{\top}, B$. unamae MTI- $641^{\top}$ and B. tropica Ppe $8^{\top}$ are D0514538-DQ514540, respectively.

An extended neighbour-joining tree showing the phylogenetic position of strain $\mathrm{FeGIO} 1^{\top}$ based on its $16 \mathrm{~S}$ rRNA gene sequence is available as supplementary material in IJSEM Online. writing includes more than 40 species. Members of the genus Burkholderia have been found within many different ecological niches, but predominantly within the soil and the rhizosphere, from which some of the more recently described species have been isolated, such as Burkholderia sacchari (Brämer et al., 2001), Burkholderia tropica (Reis et al., 2004) and Burkholderia unamae (Caballero-Mellado et al., 2004).

Functionally, Burkholderia is a remarkably diverse genus that includes plant symbionts and both plant and animal pathogens. Some species of the genus are also known as opportunistic pathogens in humans. Certain species of Burkholderia have proved to be very efficient in biocontrol, bioremediation and plant growth promotion (Coenye \& Vandamme, 2003; O'Sullivan \& Mahenthiralingam, 2005). 
Many strains of Burkholderia species have, among other properties, the ability to solubilize highly insoluble phosphatic minerals and, therefore, are of significant interest to the agricultural sector with regard to their applicability in biofertilization (Artursson et al., 2006; Igual et al., 2001; Peix et al., 2001; Purnomo et al., 2005). Moreover, this property could also be economically useful for emerging industries such as biomining. Many of the current world iron ore resources contain over $0.08 \%(\mathrm{w} / \mathrm{w})$ phosphorus, a level above the accepted standard for the manufacture of metallic iron and steel (Cheng et al., 1999). Although there are chemical processes to reduce the phosphorus content of iron ores, the historically low prices of this raw material make them non-viable economically. In this context, biotechnology may have a role in overcoming this problem in a cost-effective and environmentfriendly way. In the course of isolating phosphate-solubilizing micro-organisms (PSMs) from a high-phosphorous iron ore from Minas Gerais State, Brazil, we isolated a bacterial strain, designated $\mathrm{FeGl} 1^{\mathrm{T}}$, that, based on its genotypic and phenotypic characterization, should be classified within a novel species of the genus Burkholderia.

Strain $\mathrm{FeGl01}{ }^{\mathrm{T}}$ was isolated from a suspension of the ore material in sterile distilled water maintained under agitation for $24 \mathrm{~h}$ at ambient temperature. The suspension was serially diluted and spread on NBRIP agar plates. The medium NBRIP was described by Nautiyal (1999) for the detection of PSMs, and contains glucose as a carbon source and insoluble tricalcium phosphate as the sole source of phosphorus, allowing the detection of PSMs based on the formation of haloes around their colonies. Cultures used in further studies were purified from a single colony after 12 days incubation at $30^{\circ} \mathrm{C}$ on NBRIP medium, and subsequently cultivated on YED-P agar plates. On YED-P, colonies of strain $\mathrm{FeGl} 01^{\mathrm{T}}$ were cream-coloured, circular, smooth and convex with diameters of $1-3 \mathrm{~mm}$.

Genomic DNA was extracted as described by Rivas et al. (2001). The $16 \mathrm{~S}$ rRNA gene of strain $\mathrm{FeGl} 01^{\mathrm{T}}$ was analysed as described by Rivas et al. (2002). The sequence obtained was compared with those from GenBank using the FASTA program (Pearson \& Lipman, 1988). Sequences were aligned using CLUSTAL X software (Thompson et al., 1997). Distances were calculated according to Kimura's twoparameter method (Kimura, 1980). The phylogenetic tree was inferred using the neighbour-joining method (Saitou \& Nei, 1987), and bootstrap analysis was based on 1000 resamplings. The MEGA2.1 package (Kumar et al., 2001) was used for all analyses. A neighbour-joining tree showing the phylogenetic position of strain $\mathrm{FeGl}_{01}{ }^{\mathrm{T}}$ based on its $16 \mathrm{~S}$ rRNA gene sequence is presented in Fig. 1 (an extended tree is shown in Supplementary Fig. S1 available in IJSEM Online). The results of the phylogenetic analysis indicate that strain $\mathrm{FeGl} 01^{\mathrm{T}}$ is related to members of the genus Burkholderia. The closest relatives to strain $\mathrm{FeGl} 1^{\mathrm{T}}$ among recognized species of the genus Burkholderia are B. sacchari LMG $19450^{\mathrm{T}}$, B. tropica Ppe ${ }^{\mathrm{T}}$ and B. unamae MTI-641 ${ }^{\mathrm{T}}$

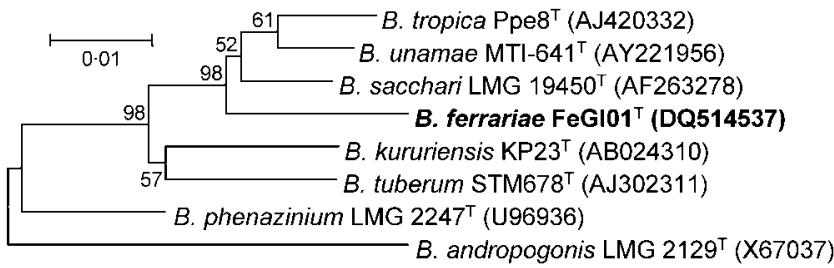

Fig. 1. Neighbour-joining tree based on nearly complete $16 \mathrm{~S}$ rRNA gene sequences showing relatedness among strain $\mathrm{FeGlO1}^{\top}$ and its closest relatives. The phylogenetic tree was rooted with $B$. andropogonis LMG $2129^{\top}$ as the outgroup sequence. The significance of each branch is indicated by a bootstrap value calculated for 1000 subsets. Bar, 1 substitution per $100 \mathrm{nt}$. An extended tree is available as Supplementary Fig. S1 in IJSEM Online.

showing, respectively, 16S rRNA gene sequence similarities of $97 \cdot 6,97 \cdot 3$ and $97 \cdot 0 \%$. Two recently described Burkholderia species are also very closely related to strain FeGl01 ${ }^{\mathrm{T}}$ : Burkholderia silvatlantica SRMrh- $20^{\mathrm{T}}$ and Burkholderia mimosarum PAS44 ${ }^{\mathrm{T}}$ show $16 \mathrm{~S}$ rRNA gene sequence similarities of $97 \cdot 4$ and $97 \cdot 6 \%$, respectively, to strain $\mathrm{FeGl01}{ }^{\mathrm{T}}$. The low similarities found between strain $\mathrm{FeGlO1}^{\mathrm{T}}$ and its closest relatives suggest that it represents a novel species of the genus Burkholderia.

According to the results of Payne et al. (2005), Burkholderia species can be differentiated by analysis of an internal 385bp sequence of the recA gene (spanning bases 76 to 461 relative to the Burkholderia cenocepacia J2315 genome recA gene). Moreover, Payne et al. (2005) also reported that analysis of this partial $\operatorname{rec} A$ sequence, obtained with the Burkholderia-specific primers BUR3 and BUR4, produced phylogenetic trees with the same topology and discrimination as those derived from analysis of nearly full-length recA gene sequences. Although the recA analysis does not exactly match the phylogeny obtained with $16 \mathrm{~S}$ rRNA gene sequences, it provides a greater degree of resolution among closely related species within the genus (Payne et al., 2005). Thus, to confirm the phylogenetic position of strain $\mathrm{FeGl01}{ }^{\mathrm{T}}$, we amplified and sequenced this partial recA region for strain $\mathrm{FeGl} 01^{\mathrm{T}}$, B. tropica Ppe ${ }^{\mathrm{T}}$ and B. unamae MTI- $641^{\mathrm{T}}$ as described by Payne et al. (2005), and these sequences were compared with those from GenBank and analysed as described above for the $16 \mathrm{~S}$ rRNA gene. A phylogenetic tree constructed with these partial recA sequences is shown in Fig. 2. The results roughly confirm the phylogenetic position of strain $\mathrm{FeGl} 01^{\mathrm{T}}$ within the genus Burkholderia obtained by analysis of $16 \mathrm{~S}$ rRNA gene sequences. Although B. tropica $\mathrm{Ppe} 8^{\mathrm{T}}$ grouped in a cluster different from that containing strain $\mathrm{FeGl} 01^{\mathrm{T}}$, B. sacchari LMG $19450^{\mathrm{T}}$ and B. unamae MTI-641 ${ }^{\mathrm{T}}$, a pairwise analysis of the partial recA sequences showed that these three recognized species are the closest relatives to strain $\mathrm{FeGl01} 1^{\mathrm{T}}$, with similarity values of $94.9 \%$ (B. sacchari $\mathrm{LMG} 19450^{\mathrm{T}}$ ), $93.5 \%$ (B. unamae MTI- $641^{\mathrm{T}}$ ) and $92 \cdot 0 \%$ (B. tropica 


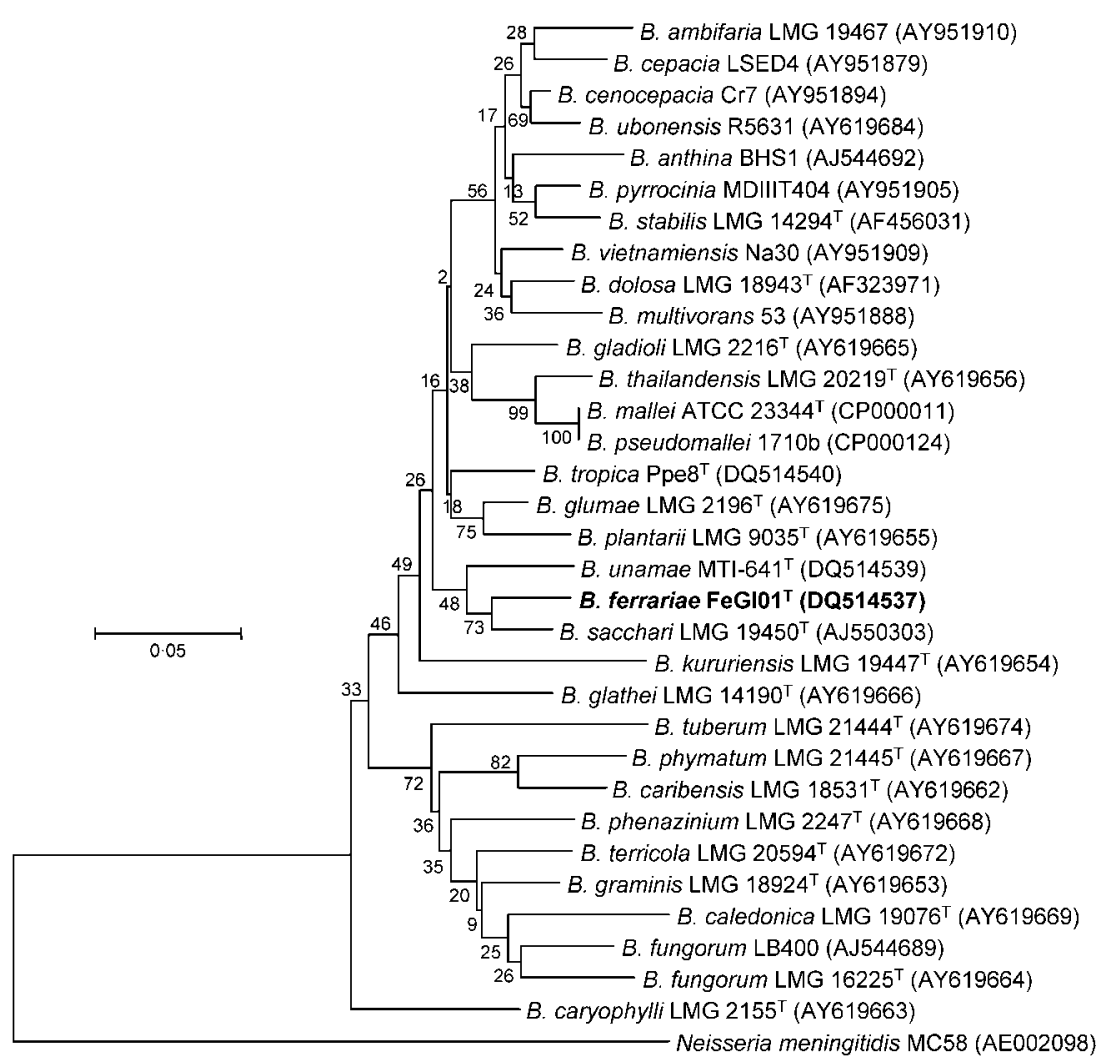

Fig. 2. Neighbour-joining tree based on partial $r e c A$ sequences of members of the genus Burkholderia. The phylogenetic tree was rooted using the Neisseria meningitidis MC58 recA gene as the outgroup sequence. The significance of each branch is indicated by a bootstrap value calculated for 1000 subsets. Bar, 5 substitutions per 100 nt.
Ppe $8^{\mathrm{T}}$ ). These $\operatorname{rec} A$ sequence similarity values suggest that strain $\mathrm{FeGl}^{\mathrm{T}}$ may belong to a novel species.

For base composition analysis, DNA was prepared according to the method of Chun \& Goodfellow (1995). The G + C content of the DNA was determined using the thermal denaturation method (Mandel \& Marmur, 1968). The G+C content of strain $\mathrm{FeGl01}^{\mathrm{T}}$ was $62 \cdot 7 \mathrm{~mol} \%$. DNA-DNA hybridization was performed according to the method of Ezaki et al. (1989), following the recommendations of Willems et al. (2001). Mean levels of DNA-DNA relatedness of $40 \%$ were found between strain $\mathrm{FeGlO1}^{\mathrm{T}}$ and both $B$. sacchari LMG $19450^{\mathrm{T}}$ and B. tropica $\mathrm{Ppe} 8^{\mathrm{T}}$, and of $24 \%$ between strain FeGl01 ${ }^{\mathrm{T}}$ and B. unamae MTI-641 ${ }^{\mathrm{T}}$ (mean of four replications). These results indicate that strain $\mathrm{FeGl}_{01}{ }^{\mathrm{T}}$ does not belong to any of the recognized species of Burkholderia based on the recommended minimum threshold value of $70 \%$ DNA-DNA relatedness for the definition of genomic species (Wayne et al., 1987).

Analyses of quinones and of the cellular fatty acid profile of strain FeGl01 ${ }^{\mathrm{T}}$ were performed at the DSMZ. As in all other species of the genus Burkholderia, ubiquinone Q-8 was detected as the predominant quinone system. The fatty acid profile of strain $\mathrm{FeGlO}^{\mathrm{T}}$ consisted of (only components comprising $>1 \%$ of the total are given): $\mathrm{C}_{14: 0}(4.9 \%)$, $\mathrm{C}_{16: 0}(18 \cdot 0 \%), \mathrm{C}_{17: 0}$ cyclo $(18 \cdot 9 \%), \mathrm{C}_{16: 1} 2-\mathrm{OH}(1 \cdot 5 \%)$, $\mathrm{C}_{16: 0} \quad 2-\mathrm{OH} \quad(5 \cdot 0 \%), \mathrm{C}_{16: 0} \quad 3-\mathrm{OH} \quad(3 \cdot 4 \%), \mathrm{C}_{18: 1} \omega 7 c$ $(16 \cdot 7 \%), \mathrm{C}_{19: 0} \omega 8 c$ cyclo $(18 \cdot 8 \%), \mathrm{C}_{18: 1} 2-\mathrm{OH}(1 \cdot 5 \%)$ and summed features $2(6 \cdot 0 \%)$ and $3(1 \cdot 9 \%)$. Summed feature 2 corresponds to $\mathrm{C}_{14: 0} 3-\mathrm{OH}$, iso- $\mathrm{C}_{16: 1} \mathrm{I}$, an unknown fatty acid with equivalent chain length of 10.928 , $\mathrm{C}_{12: 0}$ ALDE or any combination of these fatty acids, and summed feature 3 corresponds to $\mathrm{C}_{16: 1} \omega 7 c$ and/or iso- $\mathrm{C}_{15: 0}$ 2-OH. The components included in summed features 2 and 3 are similar to those reported in other Burkholderia species (Caballero-Mellado et al., 2004; Chen et al., 2006; Coenye et al., 2001; Vandamme et al., 1997). The fatty acid profile of strain $\mathrm{FeGlO}^{\mathrm{T}}$ shows significant differences from those of the phylogenetically most closely related species, $B$. sacchari (Brämer et al., 2001), B. unamae (CaballeroMellado et al., 2004) and B. mimosarum (Chen et al., 2006); the proportions of $\mathrm{C}_{17: 0}$ cyclo and $\mathrm{C}_{19: 0} \omega 8 c$ cyclo are considerably higher and the proportions of $\mathrm{C}_{18: 1} \omega 7 c$ and summed feature 3 are considerably lower in strain $\mathrm{FeGl}_{01}^{\mathrm{T}}$ than in these other three Burkholderia species. In comparison with B. silvatlantica (Perin et al., 2006), strain $\mathrm{FeGl}^{\mathrm{T}}{ }^{\mathrm{T}}$ contains relatively high proportions of both $\mathrm{C}_{19: 0} \omega 8 c$ cyclo and $\mathrm{C}_{17: 0}$ cyclo (Table 1).

Phenotypic traits of strain FeGl01 ${ }^{\mathrm{T}}$ were analysed by using the API 20NE gallery (bioMérieux) as recommended by the manufacturer, and by using the API $50 \mathrm{CH}$ galleries (bioMérieux) inoculated with a suspension of cells in $0.7 \%(\mathrm{w} / \mathrm{v})$ YNB minimal growth medium (Difco) adjusted to $\mathrm{pH} 7 \cdot 0$. Results are given in the species description below. Strain $\mathrm{FeGl}_{01}^{\mathrm{T}}$ can be differentiated from $B$. sacchari, $B$. tropica, B. unamae, B. silvatlantica and B. mimosarum by its inability to assimilate sorbitol and $D$-arabinose and from the first four of these species by its ability to assimilate dulcitol 
Table 1. Differential phenotypic characteristics of strain $\mathrm{FeGlO1}^{\top}$ and phylogenetically closely related Burkholderia species

Taxa: 1, strain $\mathrm{FeGl}^{\mathrm{T}}{ }^{\mathrm{T}}$; 2, B. sacchari (data taken from Brämer et al., 2001); 3, B. unamae (Caballero-Mellado et al., 2004); 4, B. tropica (Reis et al., 2004); 5, B. silvatlantica (Perin et al., 2006); 6, B. mimosarum (Chen et al., 2006). +, Good growth; \pm , poor growth; -, no growth; V, variable; ND, no data available.

\begin{tabular}{|lccccccc|}
\hline Characteristic & $\mathbf{1}$ & $\mathbf{2}$ & $\mathbf{3}$ & $\mathbf{4}$ & $\mathbf{5}$ & $\mathbf{6}$ \\
\hline Growth on MacConkey medium & - & - & $\mathbf{1}$ & + & - & $\mathrm{ND}$ \\
at $29{ }^{\circ} \mathrm{C}$ & & & & & & \\
Carbon source assimilation: & & & & & & \\
D-Arabinose & - & + & + & + & + & + \\
Sorbitol & - & + & + & + & + & + \\
Dulcitol & + & - & - & - & - & $\mathrm{ND}$ \\
D-Tagatose & + & - & - & - & - & $\mathrm{ND}$ \\
Ribose & + & - & - & + & + & $\mathrm{ND}$ \\
Rhamnose & - & - & + & + & + & - \\
Salicin & - & - & - & $\mathrm{V}$ & - & $\mathrm{ND}$ \\
Cellobiose & + & - & + & + & + & - \\
Lactose & - & - & - & $\mathrm{V}$ & - & - \\
Sucrose & - & + & - & - & + & - \\
Trehalose & + & - & + & $\mathrm{V}$ & - & - \\
D-Raffinose & - & + & - & - & - & - \\
$\beta$-Gentiobiose & - & - & - & + & - & - \\
D-Lyxose & - & + & - & $\mathrm{V}$ & - & $\mathrm{ND}$ \\
D-Fucose & - & + & - & + & - & + \\
Fatty acid content $(\%):$ & & & & & & \\
$\mathrm{C}_{17: 0}$ cyclo & $18 \cdot 9$ & $3 \cdot 7$ & $6 \cdot 6$ & $\mathrm{ND}$ & $14 \cdot 1$ & $3 \cdot 9$ \\
$\mathrm{C}_{19: 0} \omega 8 \mathrm{c}$ cyclo & $18 \cdot 8$ & $\mathrm{ND}$ & $3 \cdot 6$ & $\mathrm{ND}$ & $9 \cdot 4$ & $2 \cdot 0$ \\
$\mathrm{C}_{18: 1} \omega 7 c$ & $16 \cdot 7$ & $34 \cdot 0$ & $34 \cdot 2$ & $\mathrm{ND}$ & $16 \cdot 5$ & $44 \cdot 9$ \\
Summed feature $3 *$ & $1 \cdot 9$ & $23 \cdot 4$ & $15 \cdot 6$ & $\mathrm{ND}$ & $7 \cdot 5$ & $12 \cdot 7$ \\
& & & & & & & \\
\hline
\end{tabular}

${ }^{*}$ Summed feature 3 comprises $\mathrm{C}_{16: 1} \omega 7 c$ and/or iso- $\mathrm{C}_{15: 0}$ 2-OH for strain $\mathrm{FeGl01}^{\mathrm{T}}$ (B. ferrariae sp. nov.), B. unamae (Caballero-Mellado et al., 2004) and B. mimosarum (Chen et al., 2006), $C_{16: 1} \omega 7 c$ for $B$. sacchari (Brämer et al., 2001) and $\mathrm{C}_{16: 1} \omega 6 c$ and/or $\mathrm{C}_{16: 1} \omega 7 c$ for $B$. silvatlantica (Perin et al., 2006).

and D-tagatose. Other differences in the assimilation of carbon sources are given in Table 1.

Strain $\mathrm{FeGl}^{\mathrm{T}}{ }^{\mathrm{T}}$ can be differentiated genotypically and phenotypically from recognized species of the genus Burkholderia and we therefore suggest that it represents a novel species, for which the name Burkholderia ferrariae sp. nov. is proposed.

\section{Description of Burkholderia ferrariae sp. nov.}

Burkholderia ferrariae (fer.ra' ri.ae. L. gen. n. ferrariae of an iron mine).

Cells are Gram-negative, non-sporulating rods. Catalaseand oxidase-positive. Colonies on YED-P medium are cream-coloured, round, smooth and convex with diameters of approximately 1-3 $\mathrm{mm}$. Nitrate is reduced to nitrite. In the API 20NE system, it produces $\beta$-galactosidase but does not produce indole, urease, arginine dihydrolase or gelatinase; it does not hydrolyse aesculin. The following substrates are assimilated as carbon sources in the API 20NE and API 50CH systems: glycerol, L-arabinose, ribose, Dxylose, adonitol, galactose, D-glucose, D-fructose, D-mannose, dulcitol, inositol, mannitol, $N$-acetylglucosamine, cellobiose, trehalose, D-tagatose, L-fucose, D-arabitol, gluconate, 2-ketogluconate, malate, citrate, caprate, adipate and phenylacetate. It does not use erythritol, D-arabinose, Lxylose, methyl $\beta$-xyloside, L-sorbose, rhamnose, sorbitol, methyl $\alpha$-D-mannoside, methyl $\alpha$-D-glucoside, amygdalin, arbutin, salicin, maltose, lactose, melibiose, sucrose, inulin, melezitose, D-raffinose, starch, glycogen, xylitol, $\beta$-gentiobiose, D-turanose, D-lyxose, D-fucose, L-arabitol or 5ketogluconate as carbon sources. The $\mathrm{G}+\mathrm{C}$ content is $62 \cdot 7 \mathrm{~mol} \%$.

The type strain, FeGl01 ${ }^{\mathrm{T}} \quad\left(=\mathrm{LMG} \quad 23612^{\mathrm{T}}=\mathrm{CECT}\right.$ $7171^{\mathrm{T}}=\mathrm{DSM} 18251^{\mathrm{T}}$ ), was isolated from ore material from the Jangada mine, Minas Gerais State, Brazil.

\section{Acknowledgements}

We wish to thank Dr Jesús Caballero-Mellado (UNAM, Cuernavaca, Mexico) for kindly providing the type strains of $B$. unamae and $B$. tropica. A. V. is indebted to the Ministry of Education and Science of Spain for a post-doctoral fellowship at The Hebrew University of Jerusalem. P.D. acknowledges financial support, in the form of a doctoral scholarship, of the Venezuelan Foundation for Science, Technology and Innovation (FONACIT) and the Simón Bolívar University of Venezuela.

\section{References}

Artursson, V., Finlay, R. D. \& Jansson, J. K. (2006). Interactions between arbuscular mycorrhizal fungi and bacteria and their potential for stimulating plant growth. Environ Microbiol 8, 1-10.

Brämer, C. O., Vandamme, P., da Silva, L. F., Gomez, J. G. C. \& Steinbüchel, A. (2001). Burkholderia sacchari sp. nov., a polyhydroxyalkanoate-accumulating bacterium isolated from soil of a sugar-cane plantation in Brazil. Int $J$ Syst Evol Microbiol 51, 1709-1713.

Caballero-Mellado, J., Martínez-Aguilar, L., Paredes-Valdez, G. \& Estrada-de los Santos, P. (2004). Burkholderia unamae sp. nov., an $\mathrm{N}_{2}$-fixing rhizospheric and endophytic species. Int $J$ Syst Evol Microbiol 54, 1165-1172.

Chen, W.-M., James, E. K., Coenye, T. \& 7 other authors (2006). Burkholderia mimosarum sp. nov., isolated from root nodules of Mimosa spp. from Taiwan and South America. Int J Syst Evol Microbiol 56, 1847-1851.

Cheng, C. Y., Misra, V. N., Clough, J. \& Mun, R. (1999). Dephosphorisation of Western Australian iron ore by hydrometallurgical process. Miner Eng 12, 1083-1092.

Chun, J. \& Goodfellow, M. (1995). A phylogenetic analysis of the genus Nocardia with 16S rRNA sequences. Int J Syst Bacteriol 45, 240-245. 
Coenye, T. \& Vandamme, P. (2003). Diversity and significance of Burkholderia species occupying diverse ecological niches. Environ Microbiol 5, 719-729.

Coenye, T., Mahenthiralingam, E., Henry, D., LiPuma, J. J., Laevens, S., Gillis, M., Speert, D. P. \& Vandamme, P. (2001). Burkholderia ambifaria sp. nov., a novel member of the Burkholderia cepacia complex including biocontrol and cystic fibrosis-related isolates. Int J Syst Evol Microbiol 51, 1481-1490.

Ezaki, T., Hashimoto, Y. \& Yabuuchi, E. (1989). Fluorometric deoxyribonucleic acid-deoxyribonucleic acid hybridization in microdilution wells as an alternative to membrane filter hybridization in which radioisotopes are used to determine genetic relatedness among bacterial strains. Int J Syst Bacteriol 39, 224-229.

Igual, J. M., Valverde, A., Cervantes, E. \& Velázquez, E. (2001). Phosphate-solubilizing bacteria as inoculants for agriculture: use of updated molecular techniques in their study. Agronomie 21, 561-568.

Kimura, M. (1980). A simple method for estimating evolutionary rates of base substitutions through comparative studies of nucleotide sequences. J Mol Evol 16, 111-120.

Kumar, S., Tamura, K., Jakobsen, I.-B. \& Nei, M. (2001). Molecular Evolutionary Genetics Analysis software. Arizona State University, Tempe, AZ, USA.

Mandel, M. \& Marmur, J. (1968). Use of ultraviolet absorbance temperature profile for determining the guanine plus cytosine content of DNA. Methods Enzymol 12B, 195-206.

Nautiyal, C. S. (1999). An efficient microbiological growth medium for screening phosphate solubilizing microorganisms. FEMS Microbiol Lett 170, 265-270.

O'Sullivan, L. A. \& Mahenthiralingam, E. (2005). Biotechnological potential within the genus Burkholderia. Lett Appl Microbiol 41, 8-11.

Payne, G. W., Vandamme, P., Morgan, S. H., LiPuma, J. J., Coenye, T., Weightman, A. J., Jones, T. H. \& Mahenthiralingam, E. (2005). Development of a recA gene-based identification approach for the entire Burkholderia genus. Appl Environ Microbiol 71, 3917-3927.

Pearson, W. R. \& Lipman, D. J. (1988). Improved tools for biological sequence comparison. Proc Natl Acad Sci U S A 85, 2444-2448.

Peix, A., Mateos, P. F., Rodríguez-Barrueco, C., Martínez-Molina, E. \& Velázquez, E. (2001). Growth promotion of common bean (Phaseolus vulgaris L.) by a strain of Burkholderia cepacia under growth chamber conditions. Soil Biol Biochem 33, 1927-1935.

Perin, L., Martínez-Aguilar, L., Paredes-Valdez, G., Baldani, J. I., Estrada-de los Santos, P., Reis, V. M. \& Caballero-Mellado, J. (2006). Burkholderia silvatlantica sp. nov., a diazotrophic bacterium associated with sugar cane and maize. Int J Syst Evol Microbiol 56, 1931-1937.

Purnomo, E., Mursyid, A., Syarwani, M., Jumberi, A., Hashidoko, Y., Hasegawa, T., Honma, S. \& Osaki, M. (2005). Phosphorus solubilizing microorganisms in the rhizosphere of local rice varieties grown without fertilizer on acid sulfate soils. Soil Sci Plant Nutr 51, 679-681.

Reis, V. M., Estrada-de los Santos, P., Tenorio-Salgado, S. \& 10 other authors (2004). Burkholderia tropica sp. nov., a novel nitrogen-fixing, plant-associated bacterium. Int J Syst Evol Microbiol 54, 2155-2162.

Rivas, R., Velázquez, E., Valverde, A., Mateos, P. F. \& MartínezMolina, E. (2001). A two primers random amplified polymorphic DNA procedure to obtain polymerase chain reaction fingerprints of bacterial species. Electrophoresis 22, 1086-1089.

Rivas, R., Velázquez, E., Willems, A., Vizcaíno, N., Subba-Rao, N. S., Mateos, P. F., Gillis, M., Dazzo, F. B. \& Martínez-Molina, E. (2002). A new species of Devosia that forms a unique nitrogen-fixing rootnodule symbiosis with the aquatic legume Neptunia natans (L. f.) Druce. Appl Environ Microbiol 68, 5217-5222.

Saitou, N. \& Nei, M. (1987). The neighbor-joining method: a new method for reconstructing phylogenetic trees. Mol Biol Evol 4, 406-425.

Thompson, J. D., Gibson, T. J., Plewniak, F., Jeanmougin, F. \& Higgins, D. G. (1997). The CLUSTAL_X windows interface: flexible strategies for multiple sequence alignment aided by quality analysis tools. Nucleic Acids Res 25, 4876-4882.

Vandamme, P., Holmes, B., Vancanneyt, M. \& 8 other authors (1997). Occurrence of multiple genomovars of Burkholderia cepacia in cystic fibrosis patients and proposal of Burkholderia multivorans sp. nov. Int J Syst Bacteriol 47, 1188-1200.

Wayne, L. G., Brenner, D. J., Colwell, R. R. \& 9 other authors (1987). Report of the ad hoc committee on reconciliation of approaches to bacterial systematics. Int J Syst Bacteriol 37, 463-464.

Willems, A., Doignon-Bourcier, F., Goris, J., Coopman, R., de Lajudie, P., De Vos, P. \& Gillis, M. (2001). DNA-DNA hybridization study of Bradyrhizobium strains. Int J Syst Evol Microbiol 51, 13151322.

Yabuuchi, E., Kosako, Y., Oyaizu, H., Yano, I., Hotta, H., Hashimoto, Y., Ezaki, T. \& Arakawa, M. (1992). Proposal of Burkholderia gen. nov. and transfer of seven species of the genus Pseudomonas homology group II to the new genus, with the type species Burkholderia cepacia (Palleroni and Holmes 1981) comb. nov. Microbiol Immunol 36, 1251-1275. 